Research Paper

\title{
Cloning, characterization and expression of a novel laccase gene Pclac2 from Phytophthora capsici
}

\author{
Bao Zhen Feng, Peiqian Li \\ Department of Life Sciences, Yuncheng University, Yuncheng, China.
}

Submitted: October 29, 2012; Approved: April 4, 2013.

\begin{abstract}
Laccases are blue copper oxidases (E.C. 1.10.3.2) that catalyze the one-electron oxidation of phenolics, aromatic amines, and other electron-rich substrates with the concomitant reduction of $\mathrm{O}_{2}$ to $\mathrm{H}_{2} \mathrm{O}$. A novel laccase gene pclac2 and its corresponding full-length cDNA were cloned and characterized from Phytophthora capsici for the first time. The 1683 bp full-length cDNA of pclac 2 encoded a mature laccase protein containing 560 amino acids preceded by a signal peptide of 23 amino acids. The deduced protein sequence of PCLAC2 showed high similarity with other known fungal laccases and contained four copper-binding conserved domains of typical laccase protein. In order to achieve a high level secretion and full activity expression of PCLAC2, expression vector pPIC9K with the Pichia pastoris expression system was used. The recombinant PCLAC2 protein was purified and showed on SDS-PAGE as a single band with an apparent molecular weight ca. $68 \mathrm{kDa}$. The high activity of purified PCLAC2, $84 \mathrm{U} / \mathrm{mL}$, at the seventh day induced with methanol, was observed with 2,2'-azino-di-(3-ethylbenzothialozin-6-sulfonic acid) (ABTS) as substrate. The optimum $\mathrm{pH}$ and temperature for ABTS were 4.0 and $30^{\circ} \mathrm{C}$, respectively. The reported data add a new piece to the knowledge about $P$. Capsici laccase multigene family and shed light on potential function about biotechnological and industrial applications of the individual laccase isoforms in oomycetes.
\end{abstract}

Key words: Phytophthora capsici, laccase, expression, purification, activity.

\section{Introduction}

Like fungi, oomycetes have a global distribution and prosper in diverse environments. The oomycetes belong to the kingdom Stramenopile and contain a lot of pathogenic species (Baldauf et al., 2000). The genus Phytophthora contains a large number of phytopathogens, such as $P$. capsici, $P$. infestans, $P$. sojea, and so on. And most Phytophthora species are the cause of blight, crown rot, as well as stem, leaf, and fruit lesions on many plants. Moreover, the $P$. capsici has been identified as a devastating pathogen on solanaceous and cucurbitaceous hosts including pepper, cucumber, eggplant, squash, pumpkin, tomato, melon, and zucchini (Lamour and Hausbeck 2004).

Laccase (EC 1.10.3.2) is a group of enzymes called blue copper oxidases capable of oxidizing phenols and aromatic amines by reducing molecular oxygen to water. They are widely distributed in nature and have been found in plants, fungi, bacteria and insects and believed to be involved in lignin degradation and lignin biosynthesis (Gianfreda et al., 1999). Recent studies about biological function of fungal laccases have suggested this enzyme maybe play an important role in fungal morphogenesis, fungal virulence and pigmentation (Litvintseva and Henson 2002; Baldrian 2006). Laccases are also very valuable enzyme in the global carbon cycle and industrial applications, such as biodegradation of lignin without polluting the environment, degrading a wide range of different recalcitrant compounds, and biological bleaching in paper industry (Gianfreda et al., 1999).

Several laccase genes have been cloned from different fungal sources and heterologously expressed with the specific purpose of using laccase more efficiently in biotechnology (Galhaup et al., 2002; Soden et al., 2002; Xiao et al., 2006). Among many host systems, the Pi. pastoris has been considered as an excellent host system widely

Send correspondence to B.Z. Feng. Yuncheng University, Hedongdong Street 333, Yuncheng, Shanxi provience, China. E-mail: fengbaozhen@126.com. 
used in the basic research and industrial application. The $P i$. pastoris expression system offers ease of genetic manipulation, strong inducible alcohol oxidase1 (AOX1) gene promoter, the ability to perform complex eukaryotic posttranslational modifications, capacity to grow at very high cell densities, and only secreting small amount of intrinsic protein. In fact, heterologous expression has been often used as a strategy to get around the problem of obtaining laccase isoforms not easily producible in natural hosts (Bleve et al., 2008; Pezzella 2009).

Furthermore, a variety of heterologous proteins have been successfully produced to address some targets (Cereghino and Cregg 2000; Piscitelli et al., 2001). For instance, laccase from Criptococcus neoformans have been conducted expression to ascribe a pathogenic function (Williamson et al., 1998). However, to date, there have been no studies in which the laccase gene of $P$. capsici has been expressed in Pi. pastoris system. In this study, we characterized a novel laccase gene from $P$. capsici cDNA and performed expression and purification of PCLAC2 in $P i$. pastoris. Enzyme activity analysis of PCLAC2 showed high activity with ABTS as substrate, which allows further biochemical studies for laccases.

\section{Materials and Methods}

\section{Strains, vectors and culture conditions}

A virulent $P$. capsici strain Phyc12 was used and maintained at $25^{\circ} \mathrm{C}$ on $10 \%$ V8 juice agar medium as previously described (Tyler et al., 1995; Feng et al., 2010). The pPIC9K vector and GS115 Pi. pastoris strain were used for heterologous expression of Pclac2 purchased from Invitrogen. Media components including yeast extract, bactopeptone, yeast nitrogen base and casamino acids were from Difco (Detroit, MI). MD, MM, YPD, BMGY, and BMMY were all prepared following the Invitrogen expression manuals. Restriction enzymes and T4 ligase were purchased from Sigma.

\section{Total RNA isolation}

Phyc12 mycelium grown in 10\% V8 liquid medium for three days were collected and were ground in liquid nitrogen. Total RNA was extracted using a fungal RNA kit (OMEGA) following the manufacturer's recommendations. The RNA was quantified by measuring absorbance at
$260 / 280 \mathrm{~nm}$ with a spectrophotometer and the quality was examined by electrophoresis on a $1.2 \%$ formaldehyde agarose gel. $10 \mu \mathrm{g}$ of total RNA was treated 4 units of Rnase-free DNaseI (Takara) at $37^{\circ} \mathrm{C}$ for $30 \mathrm{~min}$, and then was used for reverse transcription by Omniscript RT kit (Qiagen).

\section{Cloning of laccase gene Pclac2}

Cloning of Pclac2 gene was achieved using the primers, lac-1 and lac-2 (Table 1), derived from the genome sequence of $P$. capsici (http://genome.jgi-psf.org/PhycaF7/PhycaF7.download.html). The primers were designed using Primer Express 3.0 software and the PCR parameters were as follows: $94{ }^{\circ} \mathrm{C}$ for $4 \mathrm{~min}$, then 30 cycles of $94^{\circ} \mathrm{C}$ for $1 \mathrm{~min}, 57^{\circ} \mathrm{C}$ for $45 \mathrm{~s}$, and $72{ }^{\circ} \mathrm{C}$ for $60 \mathrm{~s}$, and then $72^{\circ} \mathrm{C}$ for $10 \mathrm{~min}$ for a final extension.

\section{Construction of pPIC9K-his6-Pclac2}

In order to express Pclac2, a construct was made by insertion of the DNA encoding the mature peptide of Pclac2 into the XhoI/NotI sites of the pPIC9K vector. To obtain the mature protein, the Pclac2 cDNA was used as template with primers Lac-UPtag (including XhoI in bold and 6 *his tag underlined) and Lac-Dntag (including NotI in bold) (Table 1). PCR parameters were as follows: $94{ }^{\circ} \mathrm{C}$ for $4 \mathrm{~min}, 35$ cycles of $94{ }^{\circ} \mathrm{C}$ for $1 \mathrm{~min}, 60^{\circ} \mathrm{C}$ for $45 \mathrm{~s}, 72{ }^{\circ} \mathrm{C}$ $1 \mathrm{~min}$, and a final extension at $72^{\circ} \mathrm{C}$ for $10 \mathrm{~min}$. The PCR products were digested with XhoI and NotI, and then were cloned in XhoI-NotI-digested pPIC9K to generate expression vector $\mathrm{pPIC} 9 \mathrm{~K} /$ Pclac 2 .

The recombinant transformants were identified firstly by restriction digestion. And then plasmids with correct insertion and right open reading frame of his6-Pclac2 in pPIC9K were also confirmed by DNA sequencing.

\section{Transformation and selection of Pi. pastoris clones secreting Pclac2}

Prior to transformation of the Pi. pastoris GS115 host strain, the pPIC9K/Pclac2 was linearized with StuI to direct integration of the expression vector into the AOX1 locus, resulting in a methanol-utilisation positive $\left(\mathrm{Mut}^{+}\right)$phenotype. The Pi. pastoris host strain was then transformed by electro-poration essentially according to the Invitrogen guide-lines. Transformants $\left(\mathrm{His}^{+} / \mathrm{Mut}^{+}\right.$) were selected for

Table 1 - Primers used in this study.

\begin{tabular}{ll}
\hline Primer & Sequence(5'-3') \\
\hline lac-1 & CTCCACTGGCACGGACTCAAGC \\
lac-2 & CCGGCCTCCAAATGCCAATCGATGTGG \\
Lac-UPtag & CGTACTCGAGCACCACCACCACCACCACGACCTTGTCACTTATGACTGCGCGT \\
Lac-DNtag & CGTAGCGGCCGCCTACAACGCGTGGATGGTCGAGTTTGA \\
5'-AOX1 3'-AOX1 & GACTGGTTCCAATTGACAAGC GCAAATGGCATTCTGACATCC \\
\hline
\end{tabular}


multiple integrated copies of the vector as described previously (Fairlie et al., 1999) by transferring, $36 \mathrm{~h}$ after transformation, $\mathrm{His}^{+}$colonies grown on YPD (1\% yeast extract, $2 \%$ bactopeptone, $2 \%$ dextrose) agar plates containing G418 at concentrations of $1-4 \mathrm{mg} / \mathrm{ml}$. Resultant colonies were screened by PCR using 5'-AOX1/3'-AOX1, LacUPtag/Lac-DNtag as listed in Table 1. The obtained transformants were grown in $100 \mathrm{~mL}$ buffered methanol complex medium (BMMY) in $250 \mathrm{~mL}$ flasks and methanol added to a final concentration of $1 \%(\mathrm{v} / \mathrm{v})$ for 14 days induction at $30{ }^{\circ} \mathrm{C}$. Expression cultures were subjected to $12 \%$ SDS-PAGE analysis. The empty vector pPIC9K was used as a control.

\section{Purification of Pclac2}

For purification, the culture was collected from 1-14 days by centrifuge (Eppendorf) at $8000 \mathrm{~g}$ for $10 \mathrm{~min}$. Then the supernatant was treated with ( $\left.\mathrm{NH}_{4}\right)_{2} \mathrm{SO} 4$ at $70 \%$ saturation, the precipitate was collected by centrifugation at $10,000 \mathrm{~g}$ for $15 \mathrm{~min}$, dissolved in native binding buffer (containing $50 \mathrm{mM}$ sodium phosphate, $500 \mathrm{mM} \mathrm{NaCl}$, $10 \mathrm{mM}$ imidazole, $\mathrm{pH} 8.0$ ), and dialyzed overnight against the same buffer. The solution obtained from dialysis was loaded on a Ni-NTA column (Invitrogen, USA) which had been pre-equilibrated with the same buffer. Wash solution was first performed with the wash buffer (containing $50 \mathrm{mM}$ sodium phosphate, $500 \mathrm{mM} \mathrm{NaCl}, 20 \mathrm{mM}$ imidazole, $\mathrm{pH}$ 8.0) followed by elution. Elution was done with elution buffer (containing $50 \mathrm{mM}$ sodium phosphate, $500 \mathrm{mM} \mathrm{NaCl}, 250 \mathrm{mM}$ imidazole, $\mathrm{pH}$ 8.0). The OD280 of each fraction was taken using a UV/vis spectrophotometer. The fractions displaying the highest absorbance were analyzed on an SDS-PAGE gel. The product was designated PCLAC2.

\section{Laccase Enzyme Assay}

Laccase activity was determined with ABTS as the substrate (Bourbonnais et al., 1998). The nonphenolic dye ABTS is oxidized by laccase to the more stable and preferred state of the cation radical. The concentration of the cation radical responsible for the intense blue-green color can be correlated to enzyme activity and is read at $420 \mathrm{~nm}$ (Majcherczyk et al., 1998). Oxidation of ABTS was monitored by determining the increase in A420 ( $8420,3.6 \mathrm{x}$ $\left.10^{4} \mathrm{M}^{-1} \mathrm{~cm}^{-1}\right)$.

The reaction mixture contained $0.5 \mathrm{mM}$ substrate (ABTS), $2.8 \mathrm{~mL}$ of $0.1 \mathrm{M}$ sodium acetate buffer of $\mathrm{pH} 4.0$, $100 \mu \mathrm{L}$ of PCLAC 2 and was incubated at $30^{\circ} \mathrm{C}$ for $5 \mathrm{~min}$. Absorbance was read at $420 \mathrm{~nm}$ in a spectrophotometer against a suitable blank. One unit was defined as the amount of the laccase that oxidized $1 \mu \mathrm{mol}$ of ABTS substrate per min. Purified PCLAC2 concentration was determined by the dye-binding method using BSA as standard.

Different culture conditions of adding various carbon sources (glucose, cellulose and starch) were tested respec- tively. The obtained transformants of Pi. pastoris GS115 were grown in $100 \mathrm{~mL} \mathrm{BMMY}$ and $1 \%(\mathrm{w} / \mathrm{v})$ different carbon sources under the condition described above. Then laccases activity of culture was determined as described above.

The optimum $\mathrm{pH}$ was determined using ABTS as substrate in $0.1 \mathrm{M}$ sodium acetate buffer $(\mathrm{pH} 2.5-7.5)$. The optimum temperature for the enzyme was estimated by measuring the enzyme activity at various temperatures ranging from $20^{\circ} \mathrm{C}$ to $90^{\circ} \mathrm{C}$ in $0.1 \mathrm{M}$ sodium acetate buffer ( $\mathrm{pH} 4.0)$.

\section{Results}

\section{Cloning and analysis of laccase gene Pclac2}

One complete sequence Pclac2 gene was identified and submitted to GenBank (accession number: JQ683129). The open reading frame of Pclac2 containes $1683 \mathrm{bp}$ and encodes a polypeptide of 560 amino acid residues with a predicted molecular mass of $62.04 \mathrm{kDa}$. It contains a signal peptide of 23-amino acid residues, and has six N-glycosylation sites, but does not exhibit an intron. Figure 1 shows the structure of Pclac2, which was analyzed using the NCBI online database to confirm that Pclac2 was homologous to laccases from fungi and other oomycete pathogens. On the basis of alignment of most of the amino acid sequences, Pclac2 contains four copper-binding conserved domains of typical laccase: CuI (HWHGLNQ), CuII (HGHEEVQ), CuIII (HPFHLHAHSP), and CuIV (MHCHIDWH) as described by Fan et al. (2011) and Piontek et al. (2002). The deduced amino acid sequence of Pclac2 protein was alignmented with BLAST in the NCBI online database, which showed Pclac2 protein was closest to $P$. infestans T30-4 (XP_002896810) with an identity of $88 \%$.

\section{Transformation and Selection}

By high efficiency transformation of the StuI-linearized pPIC9K-his6-Pclac2 into the Pi. pastoris strains, about $60 \mathrm{His}^{+}$transformants of GS115 were isolated, among them 45 of GS115 had the ability to grow well on YPD medium containing G418 (2.0 mg/ml or higher). The subsequent $\mathrm{Mut}^{+}$phenotype identification showed that the $\mathrm{His}^{+} \mathrm{G} 418$-transformants obtained from GS115 were all $\mathrm{Mut}^{+}$, indicating that the StuI-linearized pPIC9K-his6Pclac2 was integrated into the AOX1 sites of Pi. pastoris genome. The genomic DNA PCR amplification with the AOX1 primers and the specific primers Lac-UPtag/LacDNtag further confirmed the correct integration of pPIC9K-his6-Pclac2 into the corresponding chromosomal locus of Pi. Pastoris (Data not shown).

\section{Expression and Purification of Pclac2}

A protein (PCLAC2) with an apparent molecular weight about $68 \mathrm{kDa}$ was detected by SDS-PAGE in the 
ATGAGTCTCAAGCGCTTCTCTGCTGTAGCATCGGCTTTATTCGCGGCTTCTATCAACCTT

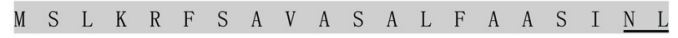
AGCGCCGCCGACCTTGTCACTTATGACTGGCGCGTTACATCTCTTTCCAGCGAGTACGAT $\begin{array}{llllllllllllllllllll}S & A & A & D & L & V & T & Y & D & W & R & V & T & S & L & S & S & E & Y & D\end{array}$ GGCGTCTACATCCACTCTCTCGGAATCAACAACAAGCCGGCCGACCAAGCTGTGATCGAC $\begin{array}{lllllllllllllllllllll}G & V & Y & I & H & S & L & G & I & N & N & K & P & A & D & Q & A & V & I & D\end{array}$ GTGGAGCTGGGCCAAGAAGTCGAGGTTCGCGTGACCAACGAGCTCGATGAGCCTACGTGT $\begin{array}{lllllllllllllllllllll}V & E & L & G & Q & E & V & E & V & R & V & T & N & E & L & D & E & P & T & C\end{array}$ CTCCACTGGCACGGACTCAAGCAGCTCGGTACTCAGGAGATGGACGGCACGTCCGAAATC $\begin{array}{lllllllllllllllllllll}L & H & \mathbb{N} & H & G & L & K & Q & L & G & T & Q & E & M & D & G & T & S & E & I\end{array}$ ACGCAGTGTCACATCGACCCGAACGGAACGGCTATCTACCGCTTCATGCCGGACAAGGCG

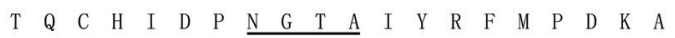
GGCACGTTCTGGTGGCACAGTCACCACATGGCGCAGTACGCGTTCGGCCTTCGTGGTCCT $\begin{array}{lllllllllllllllllllll}G & T & F & W & W & H & S & H & H & M & A & Q & Y & A & F & G & L & R & G & P\end{array}$ CTCGTTGTCCACGCCCCTGCAAATCAACGACAGGACTGGGAGAAGGACATTGACGGGGAG $\begin{array}{lllllllllllllllllllll}L & V & V & H & A & P & A & N & Q & R & Q & D & W & E & K & D & I & D & G & E\end{array}$ TACACGATTCAAATGGCGGATCTGTATCACCGGCATCCGCTGCCAACACGCATGTGGGAT AACATCCTGATCAACAACCGTGGCCGTTACAACTGCACCGCGGCAGCTCACCACAACTTC $\begin{array}{llllllllllllllllllll}N & I & L & I & N & N & R & G & R & Y & N & C & T & A & A & A & H & H & \underline{N} & F\end{array}$ ACCGAGTGCACAGACCTTCAATCGTTCTCGAAATTCCATTTCCAGGCTGGAAACAAGTAC \begin{tabular}{llllllllllllllllllll}
\hline & $E$ & $C$ & $T$ & $D$ & $L$ & $Q$ & $S$ & $F$ & $S$ & $K$ & $F$ & $H$ & $F$ & $Q$ & $A$ & $G$ & $N$ & $K$ & $Y$
\end{tabular} CTGCTCCGTCTCATCAACATGGCGGCGTTGTCCCCTATCGTCTTCAGCATTGACGACCAC $\begin{array}{llllllllllllllllllll}\text { L } & \text { L } & \text { R } & \text { L } & \text { I } & \text { N } & \text { M } & \text { A } & \text { A } & \text { L } & \text { S } & \text { P } & \text { I } & \text { V } & \text { F } & \text { S } & \text { I } & \text { D } & \text { D } & \text { H }\end{array}$ GAGTTCCGCGTTGTTGCTGCTGACGGTGACCACCTCCAGCCGTCAGAGCTCATCAACTCA

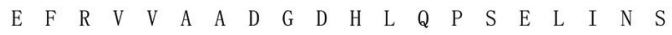
GTCACACTGAACGCCGGTCAGCGTTACGATATCGTGGTTGAAGCCAAAGCTAATTCCAAG

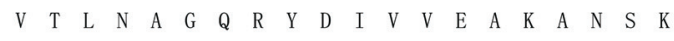
CAGAACCCAATTGGTTCCTTCTGGATGCGTGCCAATGGACTTCACGGACTTCCGTGGACA

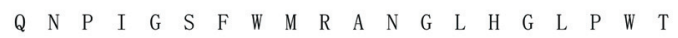
CGAGGAACGGCCGCAATCGCTGGCGAAGGCTACACGTACGAAGGCCTTGGTGTAATCTCT

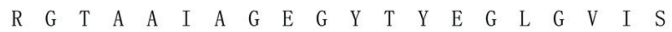
TACGATGCTGAGAGCGAGACGGACCCGACGTCACAGAAGCAACAGAACCTGACGACCATC $\begin{array}{lllllllllllllllllllll}Y & D & A & E & S & E & T & D & P & T & S & Q & K & Q & Q & N & L & T & T & I\end{array}$ AACGAGTTCGACTTCCTTCCCTTGGTGCCGATTGCCCTCCCTGAAGCTGCTTCGGACCGT $\begin{array}{llllllllllllllllllll}N & E & F & D & F & L & P & L & V & P & \text { I } & \text { A } & \text { L } & \text { P } & \text { E } & \text { A } & \text { A } & S & \text { D } & R\end{array}$ GCTGTGCTACAGTTCAAGATGCAAGATGGTAAGGGCCACTTCTCGATCGATGGTGGAGAC

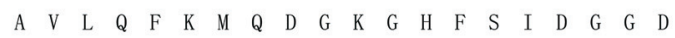
TTTAACCACTTCGTCCACCCCGAGGATCCCCCACTTTTCTCGATCGCCGGTGGTATGAAG

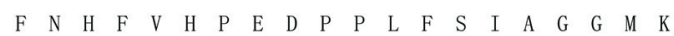
ACTGAGGAGCTTCCGGCCAACGCCAACGCTCGTAAGATCGAGTACGGCAAGCACATTGAG

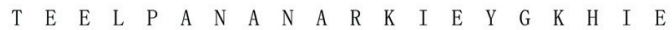
GTGGTACTGGTCAACGTCAAGGACGAACAGCACCCGTTCCACATGCACACGCATTCTCCG \begin{tabular}{llllllllllllllllllllll}
\hline & $V$ & $L$ & $V$ & $N$ & $V$ & $K$ & $D$ & $E$ & $Q$ & $H$ & $P$ & $F$ & $H$ & $M$ & $H$ & $T$ & $H$ & $S$ & $P$ \\
\hline
\end{tabular} TGGGTTGTGGGCAGCGGTGTGGCTTCGATCGAACAGATTCAGAAGAACGAGCTACCCCCT

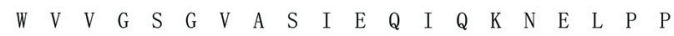
CTCAAGCTGCTTAACCCGATGACCCGTGACGTCTACACTGTCCCCCCTTGCACCTCAGAC $\begin{array}{llllllllllllllllllll}\text { L } & K & L & L & N & P & M & T & R & D & V & Y & T & V & P & P & C & T & S & D\end{array}$ GGCAAGGGCGGCTGTCTGGATGCCGGTTACCTGGTACTGCGCTTCACTGCTGACAACCCG

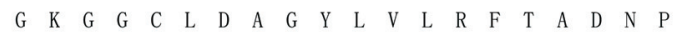
GGCGTGTGGATTTTCCACTGCCACATCGATTGGCATTTGGAGGCCGGTTTGTCGATGATC G V V W CTGGTGGAGGGCGAGGCGGAACTGCAACAAAAGGGGGTCAGTGCCTTCTCCAACACTATT $\begin{array}{llllllllllllllllllll}L & V & E & G & E & A & E & L & Q & Q & K & G & V & S & A & F & S & N & T & I\end{array}$ CTCAGTGTCTGCGGCGCTAACAGCAAGTTCTCACCGTCAAACTCGACCATCCACGCGTTG $\begin{array}{lllllllllllllllllllll}\text { L } & S & V & C & G & A & N & S & K & F & S & P & S & N & S & T & I & H & A & L\end{array}$ TAG

561

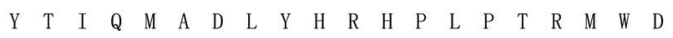

culture after methanol induction and there was no band appeared in the negative control with empty pPIC9K (Figure 2).

Due to the $6 *$ Histidine tag of PCLAC2, purification of the secreted PCLAC2 was easily achieved in small scale by using the His-bind Ni-NTA purification method. The purified PCLAC2 were then electrophoresed on SDSPAGE and a novel protein single band of approximate $68 \mathrm{kDa}$ on $12 \%$ polyacrylamide gel (Figure 2 ).

\section{PCLAC2 Activity Assay}

The activity of purified PCLAC2 was measured daily in different carbon sources growth at $30^{\circ} \mathrm{C}$ from 1-14 days (Figure 3). The maximum laccase activity (approx. $84 \mathrm{U} / \mathrm{mL}$ ) was obtained after seven-day cultivation with glucose as additional carbon source and better enzyme activity (approx. $76 \mathrm{U} / \mathrm{mL}$ ) were obtained in BMMY without complement. Cellulose and starch resulted in relatively low laccase activity. However, no extracellular laccase activity was detected in culture supernatants of the negative control (pPIC9K).

The effect of $\mathrm{pH}$ on the enzyme was determined using ABTS as substrate in $0.1 \mathrm{M}$ sodium acetate buffer at $\mathrm{pH}$ values ranging from 2.5-7.5 (Figure 4A). The optimum $\mathrm{pH}$ was for the enzyme was identified as 4.0. Meanwhile, the optimum temperature of the enzyme for ABTS oxidation was $30^{\circ} \mathrm{C}$ (Figure 4B), which was estimated by measuring the enzyme activity at various temperatures ranging from $20{ }^{\circ} \mathrm{C}$ to $90{ }^{\circ} \mathrm{C}$ in $0.1 \mathrm{M}$ sodium acetate buffer ( $\mathrm{pH} 4.0$ ).

\section{Discussion}

In the study, we have reported for the first time identified and partially characterized one laccase gene (Pclac 2 ) from a plant-pathogenic oomycete, $P$. capsici. This gene

Figure 1 - Nucleotide and deduced amino acid sequences of $p c l a c 2$. Signal peptides are in gray. Four conserved regions are shown in red box, representing $\mathrm{CuI}$ domain, $\mathrm{CuII}$ domain, $\mathrm{CuIII}$ domain, and CuIV domain respectively as previously described. Six potential $N$-glycosylation sites are underlined.

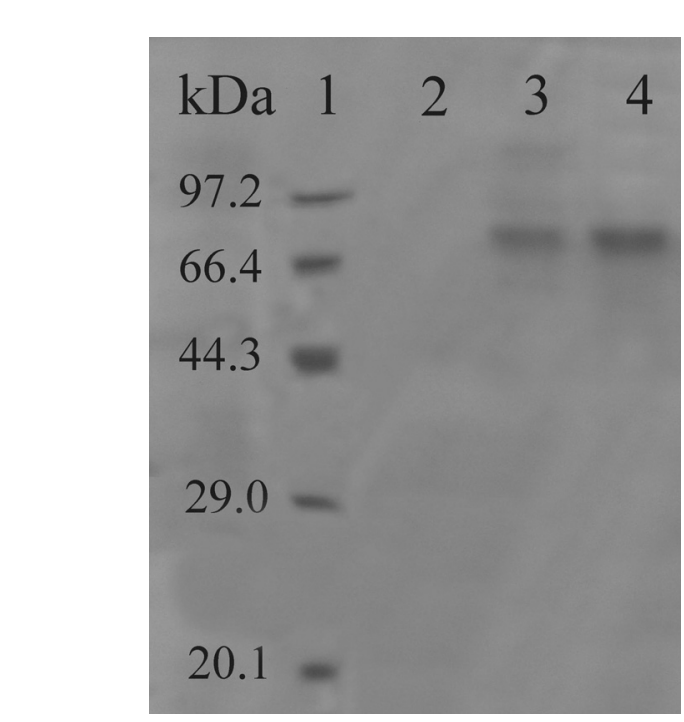

Figure 2 - The recombinant protein expression of PCLAC2 in Pi. Pastoris GS115. lane 1: low molecular weight marker; lane 2: pPIC9k (empty vector); lane 3: recombinant protein expression after induction; lane 4: $\mathrm{Pu}-$ rified PCLAC2. 

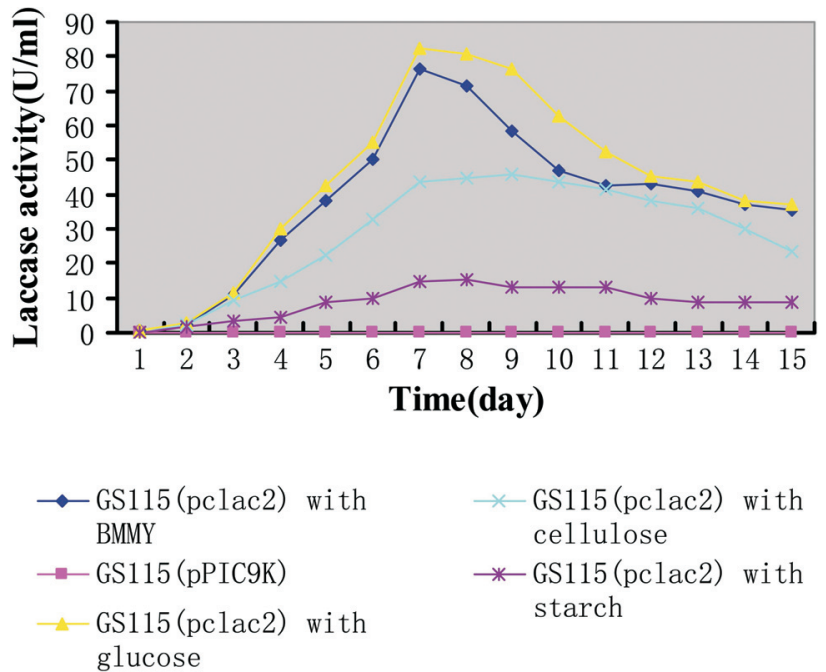

Figure 3 - Effect of various carbon sources on the activity of PCLAC2 in cultures from 1-14 days.
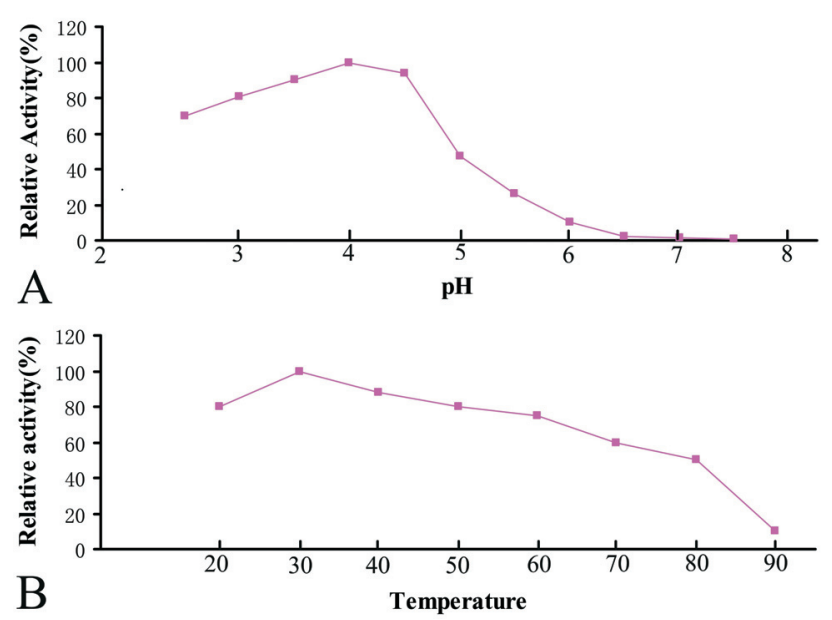

Figure 4 - Effect of $\mathrm{pH}(\mathrm{A})$ and temperature (B) on the activity of PCLAC2.

encoding active laccase was confirmed by the successful expression of Pclac2 in Pi. pastoris. Then the protein PCLAC2 was expressed and purified due to the $6 *$ Histidine tag by using the His-bind Ni-NTA purification method. And the analysis of laccase activity showed a highest yield at the seventh day after induced by $1 \%(\mathrm{v} / \mathrm{v})$ methanol at $30{ }^{\circ} \mathrm{C}$. Also we investigated the optimum $\mathrm{pH}$ and temperature of the enzyme for ABTS oxidation.

Based on multiple sequence alignments described previously, four conserved copper oxidases sites (I, II, III, and IV) acted as the copper ligands consisting of 12 amino acids (Larrondo et al., 2003). They contain one type- $1 \mathrm{Cu}$ atom (T1), bound as a mononuclear center that gives the proteins their blue color, as well as one type-2 (T2) and two type-3 (T3) Cu atoms, which together form a trinuclear center. The T1 site functions as a primary electron acceptor, extracting electrons from the substrate. Electrons are then transferred to the T2/T3 center, where reduction of molecular oxygen to water takes place (Ducros et al., 1998; McGuirl and Dooley 1999). According to a recent analysis of the Coprinus cinereus laccase crystal structure (Ducros et al., 1998) and site-directed mutagenesis studies of Myceliophthora thermophila and $R$. solani laccases (Xu et al., 1998), a pentapeptide segment located downstream of the second conserved histidine in the T1 site (H512 in Pclac2 Figure 1) has a major effect on the redox potential and specificity of the enzyme. The amino acid composition in this region was unique for Pclac2 in $P$. capsici (Figure 1), which implied that the enzymes had different substrate specificities and probably different functions in the fungus.

In the present report, we chose the Pi. pastoris expression system to express our target gene under the control of the highly methanol-inducible promoter of AOX1, and purification of the secreted protein was easily achieved due to the relatively specific $6^{*}$ histidine tag. Compared to the other expression systems, the Pi. pastoris system not only has the feature of eukaryotic protein synthesis and modification pathway, but also has its own characteristic advantages such as high level expression, protelytic processing, disulfide bridge formation, and glycosylation (Patrick et al., 2005; Shi et al., 2007). Molecular weights of most fungal laccase proteins fall between $43 \mathrm{kDa}$ and $110 \mathrm{kDa}$ (Xiao et al., 2003). And a majority of laccases from basidiomycete fungi were reported to have molecular weights in the range of $55 \mathrm{kDa}$ to $72 \mathrm{kDa}$ (Petroski et al., 1980). The result of SDS-PAGE results showed that PCLAC2 from $P$. capsici had a molecular weight ca. $68 \mathrm{kDa}$ (Figure 2), while the predicted molecular mass was $62.04 \mathrm{kDa}$. The difference could be attributed, at least partially, to glycosylation of the protein, as the deduced sequence presents six potential residues for N-glycosylation (Figure 1).

The high activity of purified PCLAC2 was observed with ABTS as substrate as reported for many other laccases like those from Pycnoporus cinnabarinus and Coriolus hirsutus (Eggert et al., 1996) and for Trichophyton rubrum laccase (Jung et al., 2002). The laccase activity was affected by several factors, including culture conditions, $\mathrm{pH}$, temperature, and so on (Hou et al., 2004; Sugareva et al., 2006; Miao et al., 2010;). In our study, the maximum laccase activity was obtained after seven-day cultivation with glucose, while cellulose and starch resulted in low laccase activity (Figure 3). The optimum $\mathrm{pH}$ was for PCLAC2 was identified as 4.0 (Figure 4A). Other studies have also reported very low optimal $\mathrm{pH}$ (between 3.0 and 5.7) for fungal laccases, except for the laccase from Rhizoctonia praticola, which exhibited a neutral optimal pH with various substrates (Park and Park 2008). Meanwhile, the optimum temperature of the PCLAC2 for ABTS oxidation was $30^{\circ} \mathrm{C}$ (Figure 4B), which was lower than the optimum temperatures previously reported for 
other fungal laccases, ranging from $40^{\circ} \mathrm{C}$ to $50^{\circ} \mathrm{C}$ (Hou et al., 2004; Park and Park 2008). PCLAC2 is a novel protein with possible biotechnological, industrial, and environmental applications, especially for the enzymatic degradation of aromatic pollutants. Consequently, further studies need to be carried out in order to determine whether the chemical and genetic characteristics of laccase present in $P$. capsici are different from others.

\section{Acknowledgments}

This research was supported by Program of University of Science and Technology of Shanxi Province (20121025), Natural Science Foundation for Young Scientists of Shanxi Province (2013021024-6) and doctoral fund of Yuncheng University (YQ-2013014).

\section{References}

Baldauf SL, Roger AJ, Wenk-Siefert I, Doolittle WF (2000) A kingdom-level phylogeny of eukaryotes based on combined protein data. Science 290:972-977.

Baldrian P (2006) Fungal laccases-occurrence and properties. FEMS Microbiol Rev 30:215-242.

Bleve G, Lezzi C, Mita G, Rampino P, Perrotta C, Villanova L, Grieco F (2008) Molecular cloning and heterologous expression of a laccase gene from Pleurotus eryngii in free and immobilized Saccharomyces cerevisiae cells. Appl Microbiol Biot 79:731-741.

Bourbonnais R, Leech D, Paice MG (1998) Electrochemical analysis of the interactions of laccase mediators with lignin model compounds. BBA-General Subjects 1379:381-390.

Cereghino JL, Cregg JM (2000) Heterologous protein expression in the methylotrophic yeast Pichia pastoris. FEMS Microbiol Rev 24:45-66.

Ducros V, Brzozowski AM, Wilson KS, Brown SH, Østergaard P, Schneider P, Yaver DS, Pedersen AH, Davies GJ (1998) Crystal structure of the type-2 $\mathrm{Cu}$ depleted laccase from Coprinus cinereus at $2.2 \AA$ resolution. Nat Struct Mol Biol 5:310-316.

Eggert C, Temp U, Eriksson KEL (1996) The lignolytic system of the white rot fungus Pycnoporus cinnabarinus: purification and characterization of the laccase. Appl Environ Micro 62:1151-1158.

Fairlie WD, Russell PK, Zhang HP, Breit SN (1999) Screening procedure for Pichia pastoris clones containing multiple copy gene inserts. Biotechniques, 26:1042-1044.

Fan F, Zhuo R, Sun S, Wan X, Jiang M, Zhang X, Yang Y (2011) Cloning and functional analysis of a new laccase gene from Trametes sp. 48424 which had the high yield of laccase and strong ability for decolorizing different dyes. Bioresource Technol 102:3126-3137.

Feng BZ, Li PQ, Wang HM, Zhang XG (2010) Functional analysis of Pcpme6 from oomycete plant pathogen Phytophthora capsici. Microb Pathogenesis 49:23-31.

Galhaup C, Goller S, Peterbauer CK, Strauss J, Haltrich D (2002) Characterization of the major laccase isoenzyme from Trametes pubescens and regulation of its synthesis by metal ions. Microbiology 148:2159-2169.
Gianfreda L, Xu F, Bollag JM (1999) Laccases: a useful group of oxidoreductive enzymes. Bioremediat J 3:1-25.

Hou HM, Zhou JT, Wang J, Du CH, Yan B (2004) Enhancement of laccase production by Pleurotus ostreatus and its use for the decolorization of anthraquinone dye. Process Biochem 39:1415-1419.

Jung H, Xu F, Li K (2002) Purification and characterization of laccase from wood-degrading fungus Trichophyton rubrum LKY-7. Enzyme Microb Tech 30:161-168.

Lamour KH, Hausbeck MK (2004) Phytophthora capsici on vegetable crops: research progress and management challenges. Plant Dis 88:1292-1303.

Larrondo LF, Salas L, Melo F, Vicuña R, Cullen D (2003) A novel extracellular multicopper oxidase from Phanerochaete chrysosporium with ferroxidase activity. Appl Environ Microb 69:6257-6263.

Litvintseva AP, Henson JM (2002) Cloning, characterization, and transcription of three laccase genes from Gaeumannomyces graminis var. tritici, the Take-All fungus. Appl Environ Microb 68:1305-1311.

Majcherczyk A, Johannes C, Hüttermann A (1998) Oxidation of polycyclic aromatic hydrocarbons (PAH) by laccase of Trametes versicolor. Enzyme Microb Tech 22:335-341.

McGuirl M, Dooley D (1999) Copper-containing oxidases. Curr Opin Chem Biol 3:138-144.

Miao L, Zhang GQ, Wang HX, Ng T (2010) Purification and characterization of a laccase from the edible wild mushroom Tricholoma mongolicum. J Microbiol Biotechn 20:10691076.

Park KM, Park S (2008) Purification and characterization of laccase from Basidiomycete Fomitella fraxinea. J Microbiol Biotechnol 18:670-675.

Patrick SM, Fazenda ML, McNeil B, Harvey LM (2005) Heterologous protein production using the Pichia pastoris expression system. Yeast 22:249-270.

Petroski RJ, Peczynska-Czoch W, Rosazza JP (1980) Analysis, production and isolation of an extracellular laccase from Polyporus anceps. Appl Environ Microb 40:1003-1006.

Pezzella C, Autore F, Giardina P, Piscitelli A, Sannia G, Faraco V (2009) The Pleurotus ostreatus laccase multi-gene family: isolation and heterologous expression of new family members. Curr Genet 55:45-57.

Piontek K, Antorini M, Choinowski T (2002) Crystal structure of a laccase from the fungus Trametes versicolor at 1.90-Å resolution containing a full complement of coppers. J Biol Chem 277:37663-37669.

Piscitelli A, Pezzella C, Gi Sun ardina P, Faraco V, Sannia G (2010) Heterologous laccase production and its role in industrial applications. Bioeng Bugs 1:252-262.

Shi J, Zhang ST, Zhang XJ, Xu H, Guo AG (2007) Expression, purification, and activity identification of alfimeprase in Pichia pastoris. Protein Expres Purif 54:240-246.

Soden DM, O'Callaghan J, Dobson ADW (2002) Molecular cloning of a laccase isozyme gene from Pleurotus sajor-caju and expression in the heterologous Pichia pastoris host. Microbiology 148:4003-4014.

Sugareva V, Härtl A, Brock M, Hübner K, Rohde M, Heinekamp T, Brakhage AA (2006) Characterisation of the laccaseencoding gene $a b r 2$ of the dihydroxynaphthalene-like melanin gene cluster of Aspergillus fumigatus. Arch Microbiol 186:345-355. 
Tyler BM, Forster H, Coffey MD (1995) Inheritance of avirulence factors and restriction fragment length polymorphism markers in outcrosses of the oomycete Phytophthora sojae. Mol Plant Microbe In 8:515-523.

Williamson PR, Wakamatsu K, Ito S (1998) Melanin biosynthesis in Cryptococcus neoformans. J Bacteriol 180:1570-1572.

Xiao YZ, Hong YZ, Li JF, Hang J, Tong PG, Fang W, Zhou CZ (2006) Cloning of novel laccase isozyme genes from Trametes sp. AH28-2 and analyses of their differential expression. Appl Microbiol Biot 71:493-501.

Xiao YZ, Tu XM, Wang J, Zhang M, Cheng Q, Zeng W, Shi Y (2003) Purification, molecular characterization and reactiv- ity with aromatic compounds of a laccase from basidiomycete Trametes $s p$. strain AH28-2. Appl Microbiol Biot 60:700-707.

Xu F, Berka RM, Wahleihner JA, Nelson BA, Shuster JR, Brown SH, Palmer AE, Solomon EI (1998) Site-directed mutations in fungal laccase: effect on redox potential, activity and $\mathrm{pH}$ profile. Biochem J 334:63-70.

All the content of the journal, except where otherwise noted, is licensed under a Creative Commons License CC BY-NC. 